\title{
COMPETITIVIDADE E LONGEVIDADE - OS DESAFIOS DO ALTO-FORNO 3 DA USIMINAS EM SUA 4를 CAMPANHA*
}

\author{
Mauro Vivaldino Fernandes ${ }^{1}$ \\ Larissa Rodrigues de Carvalho Rocha² \\ Adriano Cesar Carvalhido ${ }^{3}$ \\ Heltom Muzzi Martins ${ }^{4}$
}

\section{Resumo}

Os desafios para o aprimoramento do desempenho operacional dos altos-fornos constituem um campo aberto para o desenvolvimento e aplicação de métodos de controle que promovam a otimização da operação do reator, aliada ao prolongamento da sua vida útil. O Alto-Forno 3 da Usiminas - Ipatinga, nesta sua $4^{a}$ campanha, foi projetado para 15 anos de operação, com uma produção estimada de 41 milhões de toneladas de gusa. Os resultados da campanha atual, em termos de produção e de duração da campanha, superam os dados projetados. Neste contexto, são apresentadas as principais características do Alto-Forno 3 na sua atual campanha, a evolução do seu desempenho em termos de produtividade e tempo de operação, além das principais ações direcionadas para a preservação e estabilidade do sistema de refrigeração e do cadinho, contribuindo para o prolongamento da sua vida útil. Como resultado destes esforços, a vida útil estimada do Alto-Forno 3 é de 22 anos, superando em 7 anos a duração prevista.

Palavras-chave: Alto-Forno; Vida Útil; Staves; Cadinho; Campanha.

\section{COMPETITIVENESS AND LONGEVITY - THE CHALLENGES OF USIMINAS BLAST FURNACE \#3 IN ITS $4^{\text {th }}$ CAMPAIGN}

\section{Abstract}

The challenges for the improvement of the operational performance of the blast furnaces constitute an open field for the development and application of control methods that promote the optimization of the reactor operation associate with the lifetime extension. The Usiminas Blast Furnace \#3 of Ipatinga plant's, in its $4^{\text {th }}$ campaign was projected for 15 years of operation, with an estimated production of 41 million tons of hot metal. The results of the current campaign, in terms of production and campaign duration, outperform the projected data. In this context, the main characteristics of Blast Furnace \#3 in its current campaign are presented, the evolution of its performance in terms of productivity and operating time, as well as the main actions aimed at the preservation and stability of the refrigeration system and hearth, which contribute to extend the blast furnace lifetime. As a result of these efforts, the estimated lifetime of Blast Furnace \#3 is 22 years, 7 years longer than the expected duration.

Keywords: Blast Furnace; Lifetime; Staves; Hearth; Campaign.

1. Membro da ABM; Engenheiro Metalurgista, M. Sc., Gerente Técnico de Redução, Gerência-Geral de Redução; Ipatinga, MG, Brasil.

2. Engenheira Metalurgista, Pesquisadora, Centro de Pesquisa e Desenvolvimento da Usiminas; Ipatinga, MG, Brasil.

3. Engenheiro Mecânico, Engenheiro de Produção, Gerência-Geral de Redução; Ipatinga, MG, Brasil.

4. Engenheiro Metalurgista, Gerente Geral de Redução, Dir Exe Produção Usina de Ipatinga; Ipatinga, MG, Brasil. 


\section{INTRODUÇÃO}

A etapa de redução dos minérios de ferro em alto-forno é um dos estágios mais importantes da produção de aço em uma indústria siderúrgica. Neste reator o objetivo final é produzir, a um custo reduzido e sem problemas de ordem operacional, a quantidade necessária de gusa dentro de especificações de qualidade requeridas para o seu posterior processamento. Além disso, em busca de manter a competitividade diante do cenário econômico mundial, torna-se essencial adotar soluções que visem preservar os equipamentos e intensificar as medidas de controle do processo.

Apesar de todos os esforços empreendidos até então, os desafios para o aprimoramento do desempenho operacional dos altos-fornos não se esgotaram, constituindo ainda um campo aberto para o desenvolvimento e aplicação de métodos que promovam a otimização da operação do reator aliada ao prolongamento da sua vida útil.

Neste contexto, são apresentadas as principais características do Alto-Forno 3 na sua atual campanha (4⿳亠丷⿵冂⿱⺊口灬 campanha), a evolução do seu desempenho em termos de produtividade e tempo de operação desde a reforma, além das principais ações direcionadas para a preservação e estabilidade do sistema de refrigeração (do tipo stave cooler) e do cadinho, que contribuem para garantir o prolongamento da sua vida útil. Contempla-se também as perpectivas da Usiminas para os próximos anos.

\section{PRINCIPAIS CARACTERÍSTICAS DO ALTO-FORNO 3 INCORPORADAS NA REFORMA}

A última reforma do Alto-Forno 3 ocorreu em outubro/1999, dando início à sua 4a campanha. Com a mudança do sistema de refrigeração com placas, para refrigeração com staves, o perfil interno do forno foi totalmente modificado. No cadinho, uma grande melhoria implementada, além da adoção dos staves, foi a qualidade do material refratário utilizado, visando maior vida útil do equipamento. Além disso, foram realizadas alterações em equipamentos auxiliares como perfuradores, canhões e granuladores de escória, proporcionando melhor controle operacional [1].

$\mathrm{Na}$ tabela 1 são apresentadas as principais alterações nas características do AltoForno 3, comparando a atual campanha com a anterior.

Tabela 1. Principais características do Alto-Forno 3

\begin{tabular}{|c|c|c|}
\hline Itens & Campanha Anterior & Campanha Atual \\
\hline Blow in & Julho/1987 (3a) & Outubro/1999 (4a) \\
\hline Volume Interno $\left(\mathrm{m}^{3}\right)$ & 2.700 & 3.163 \\
\hline Volume de Trabalho $\left(\mathrm{m}^{3}\right)$ & 2.380 & 2.722 \\
\hline Ventaneiras / Furo de Gusa & $28 / 3$ & $30 / 3$ \\
\hline Lança de Injeção de Carvão & Lança Simples & Dupla Lança \\
\hline Pressão de Topo $\left(\mathrm{Kgf} / \mathrm{cm}^{2}\right)$ & 2,00 & 2,50 \\
\hline Diâmetro do Cadinho (m) & 11,50 & 12,20 \\
\hline Perfuradores & Pneumáticos & Hidráulicos \\
\hline Canhões & IHI & PW \\
\hline Granulador de Escória & RASA & INBA \\
\hline Revestimento do Cadinho & Microporo & Ultrasupermicroporo \\
\hline Blocos do Furo de Gusa & Alta Alumina & Carbono \\
\hline Tipo de Carregamento & Cone + Placas Móveis & Cone + Placas Móveis \\
\hline Sistema de Refrigeração & Placas & Staves \\
\hline Regeneradores & 3 (Cowper) & 3 (Cowper) \\
\hline Soprador & Turbo Soprador $\left(\mathrm{P}_{\text {MÁx }}=3,2 \mathrm{Kgf} / \mathrm{cm}^{2}\right)$ & Turbo Soprador $\left(\mathrm{P}_{\text {MÁx }}=4,2 \mathrm{Kgf} / \mathrm{cm}^{2}\right)$ \\
\hline Geração de Energia & Não & Turbina de Topo \\
\hline
\end{tabular}




\section{RESULTADOS OPERACIONAIS COMPARATIVOS DO ALTO-FORNO 3}

\subsection{Produção}

Em função da alteração do tipo de refrigeração ao longo do corpo do forno (placas de refrigeração foram trocadas por stave cooler), na atual campanha, o volume interno do Alto-Forno 3 teve aumento de 17,1\% em relação à campanha anterior, refletindo diretamente na sua produção de gusa.

$\mathrm{Na}$ figura 1 podem ser observados os resultados comparativos de produção acumulada e vida útil do Alto-Forno 3 nas seguintes condições: (i) resultados da última campanha; (ii) valores estimados de acordo com o projeto da atual campanha; (iii) resultados reais da atual campanha atualizados até fevereiro/2017; (iv) resultados projetados até 2021, quando estima-se o fim da campanha de acordo com cálculos baseados em resultados operacionais.

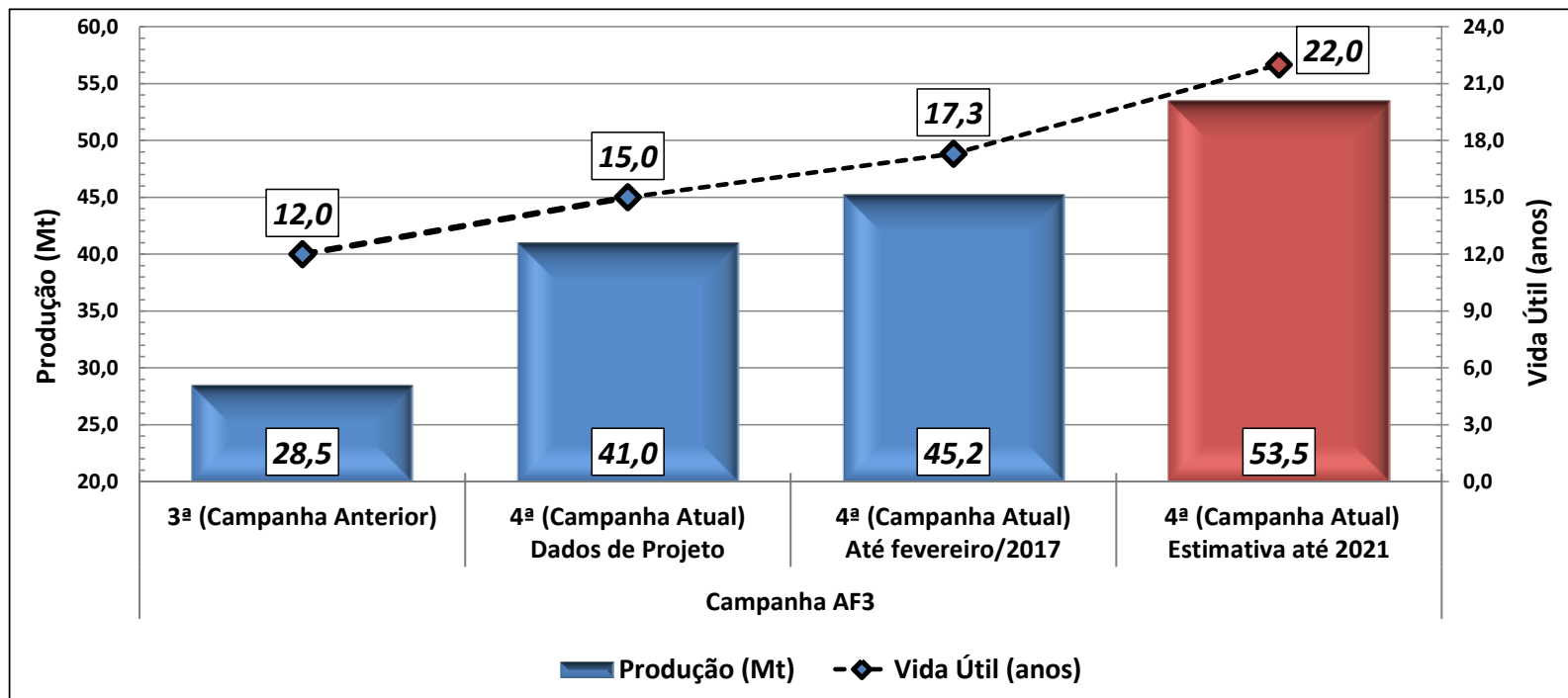

Figura 1. Comparativo dos resultados da produção acumulada e vida útil entre a campanha anterior e a atual (projeto, atual e projeção) do Alto-Forno 3.

Os resultados da campanha atual mostram uma evolução que refletem ações nas áreas de engenharia, de operação, de pesquisa e de manutenção. Ao aumentar o tempo de vida útil, aumentam as dificuldades para manutenção dos equipamentos.

É interessante citar que se a estimativa para o fim da vida útil for concretizada, a 4a campanha do Alto-Forno 3 poderá totalizar 22 anos de duração, superando em 7 anos a duração prevista no seu projeto e, em aproximadamente, 10 anos o tempo de operação na campanha anterior.

A campanha anterior privilegiou a produção, na qual obteve-se uma produtividade média de $2,42 \mathrm{t} / \mathrm{d} \cdot \mathrm{m}^{3}$ de volume interno, destaque na siderurgia mundial. 


\subsection{Produtividade}

Na figura 2 são apresentados os resultados comparativos da produtividade média e produtividade acumulada do Alto-Forno 3 nas mesmas condições descritas anteriormente, considerando o volume interno no cálculo.

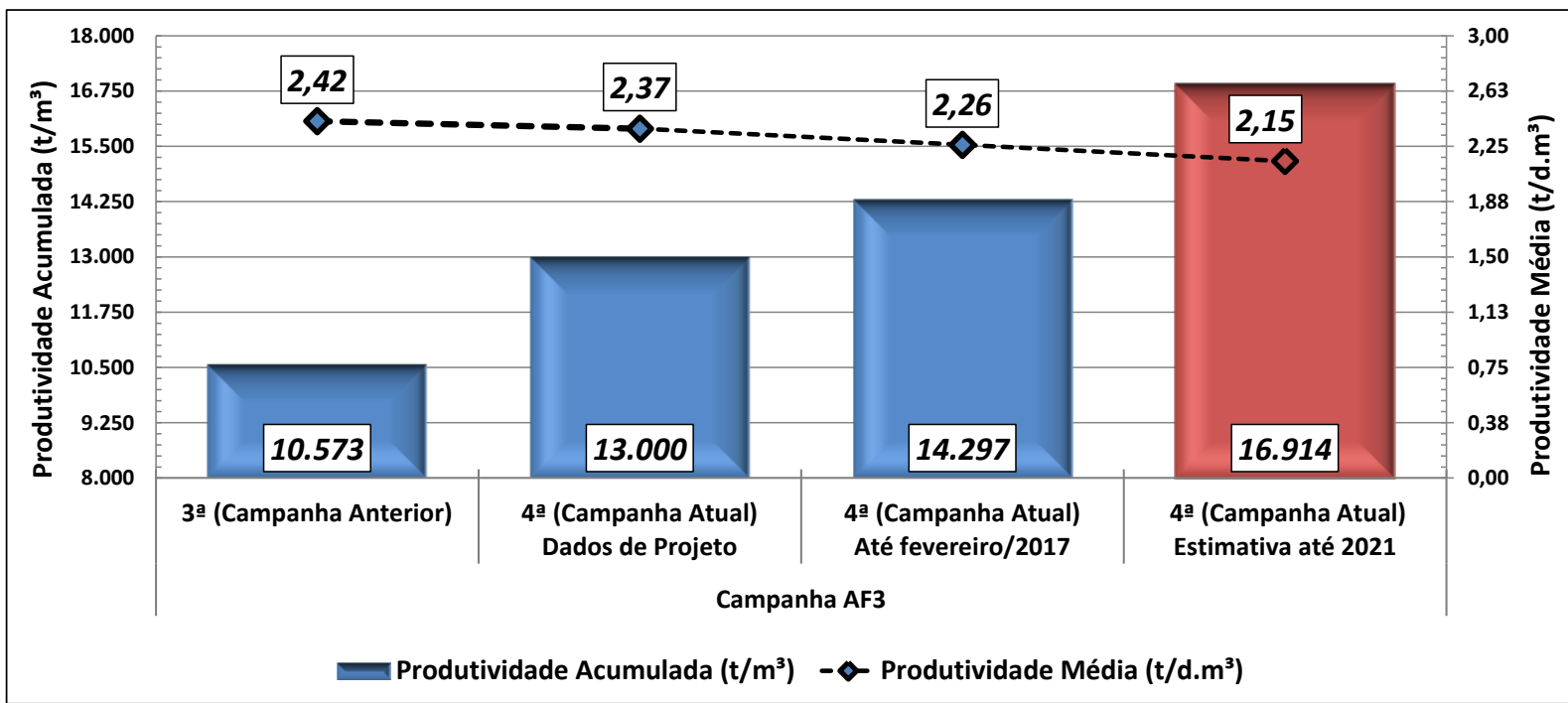

Figura 2. Comparativo dos resultados de produtividade média e acumulada entre a campanha anterior e a atual (projeto, atual e projeção) do Alto-Forno 3.

Considerando uma série de melhorias implementadas na última reforma, o AltoForno 3 foi projetado para uma produtividade média de 2,37 t/d. $\mathrm{m}^{3}$. Nos primeiros anos da campanha, durante o período de 2001 a 2008, foi mantida uma alta produtividade (média de 2,51 t/d. $\mathrm{m}^{3}$ ) e produção diária $7.900 \mathrm{t}$. Entretanto, vislumbrou-se a necessidade de operar o Alto-Forno reforçando as medidas protetivas já praticadas para este reator e adotando medidas adicionais, principalmente pela instabilidade nas temperaturas do cadinho e pela evolução do desgaste dos staves de ferro fundido. Ocorreu, então, uma redução gradual da produção ao longo dos últimos anos. O nível de produção também foi afetado, em períodos distintos, pela crise mundial de 2008/2009 e pela retração da economia brasileira.

A limitação da produtividade possibilita o aumento da duração da campanha e é uma filosofia adotada por algumas empresas, em detrimento de outras que usam a estratégia de operar com produtividade máxima no alto-forno, porém com duração de vida útil menor. Atualmente, o Alto-Forno 3 está operando com uma produção diária de aproximadamente 7.000 t.

Para garantir os resultados positivos é primordial o controle das matérias-primas enfornadas, a qualidade do coque e do sínter consumidos, o controle e acompanhamento dos parâmetros operacionais do alto-forno, visando sempre a estabilidade do reator. O aprimoramento das práticas relacionadas à manutenção dos equipamentos e a execução de ações voltadas à preservação do alto-forno e estabilidade operacional, também asseguram o prolongamento da sua vida útil. 


\section{PRINCIPAIS AÇÕES PARA A PRESERVAÇÃO DO ALTO-FORNO 3}

\subsection{Sistema de Refrigeração}

O sistema de refrigeração implantado na campanha atual (outubro/1999) é do tipo stave cooler de ferro fundido nodular, de quarta geração, projetados, fabricados e montados com supervisão da Nippon Steel \& Sumitomo Metal Corporation (NSSMC).

A evolução do desgaste dos staves é acompanhada por meio de sondagens em furos específicos, realizadas durante as paradas programadas. Os sinais de desgastes mais significativos dos staves foram obervados a partir de 2010, com a maior frequência de tubos furados e envermelhamento/fagulhamento na carcaça, impactando na refrigeração e preservação da carcaça do Alto-Forno, além de causar perda de produção em consequência de reduções de parâmetros operacionais e paradas de sopro.

Então, com a evidência dessas ocorrências, tornou-se necessária a realização de várias ações visando manter a eficiência do sistema de refrigeração do Alto-Forno, buscar estabilidade das condições de operação (reduzir número de paradas do AltoForno 3) e evitar acidentes operacionais.

\subsubsection{Instalação de by pass nos tubos furados, cigar cooler e injeção de massa}

O primeiro registro de queima de tubo de stave ocorreu em 2008, porém, em 2010, devido à maior criticidade do desgate, foi iniciada a instalação de by pass para isolamento dos tubos furados, garantindo a refrigeração da região deficiente sem a necessidade de parada do Alto-Forno.

A partir de maio/2011, após o primeiro episódio de furo na carcaça, adotou-se também a prática de instalação de cigar coolers e placas de refrigeração. Estas ações foram intensificadas ao longo dos anos, na tentativa de controlar o desgaste e manter a integridade da carcaça. A evolução do número de tubos furados nos staves em conjunto com a instalação dos cigars é apresentada na figura 3.

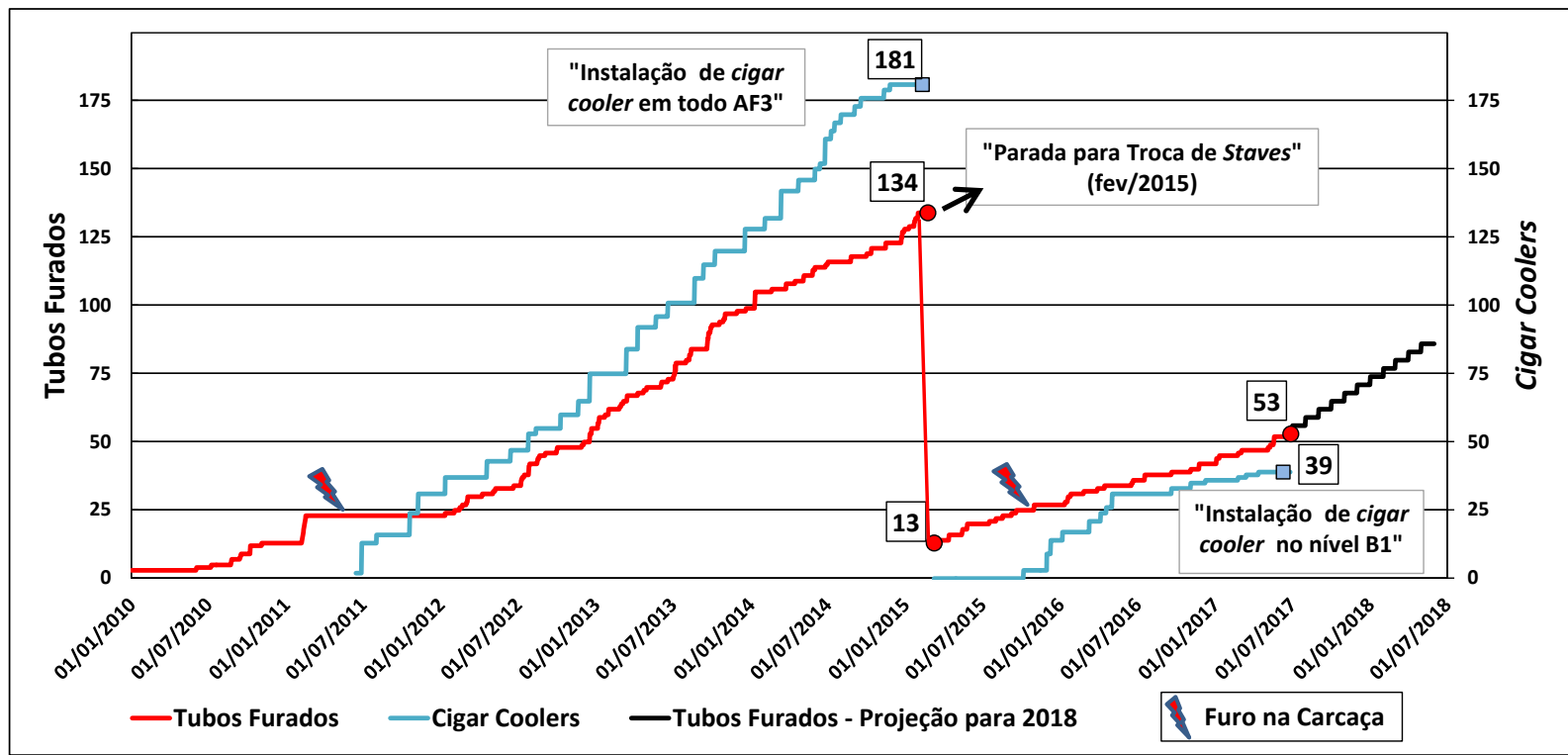

Figura 3. Evolução do número de tubos furados nos staves e instalação de cigar coolers no AltoForno 3. 
Em novembro/2015, ocorreu um furo na carcaça, entre os níveis B1 e B2 (ângulo $200^{\circ}$ ), em uma região com poucos cigar coolers para reforçar a refrigeração. Após a elevação da frequência da instalação de cigar coolers não houve mais episódios de furo na carcaça nessa região. É importante ressaltar que, associado à instalação dos cigars, ocorre a injeção de massa refratária, evitando que estes sejam danificados durante a descida de carga. De acordo com os resultados práticos, a partir da instalação dos cigars, entende-se que este recurso, aliado à outros aspectos, é eficiente em termos de controle do desgaste dos staves e integridade da carcaça.

É realizada também, em toda parada de sopro do Alto-Forno, a injeção de massa refratária_na face quente dos staves, para proteção dos tubos em função do desgaste.

\subsubsection{Troca de staves e de parte da carcaça}

Buscando uma maior estabilidade operacional e uma redução nas intervenções no Alto-Forno, foi realizada, em fevereiro/2015, a primeira troca de staves e substituição de parte da carcaça no nível B3. Foram substituídos 32 staves de ferro fundido por staves de cobre, nos níveis B3, S1 e S2, conforme figura 4.
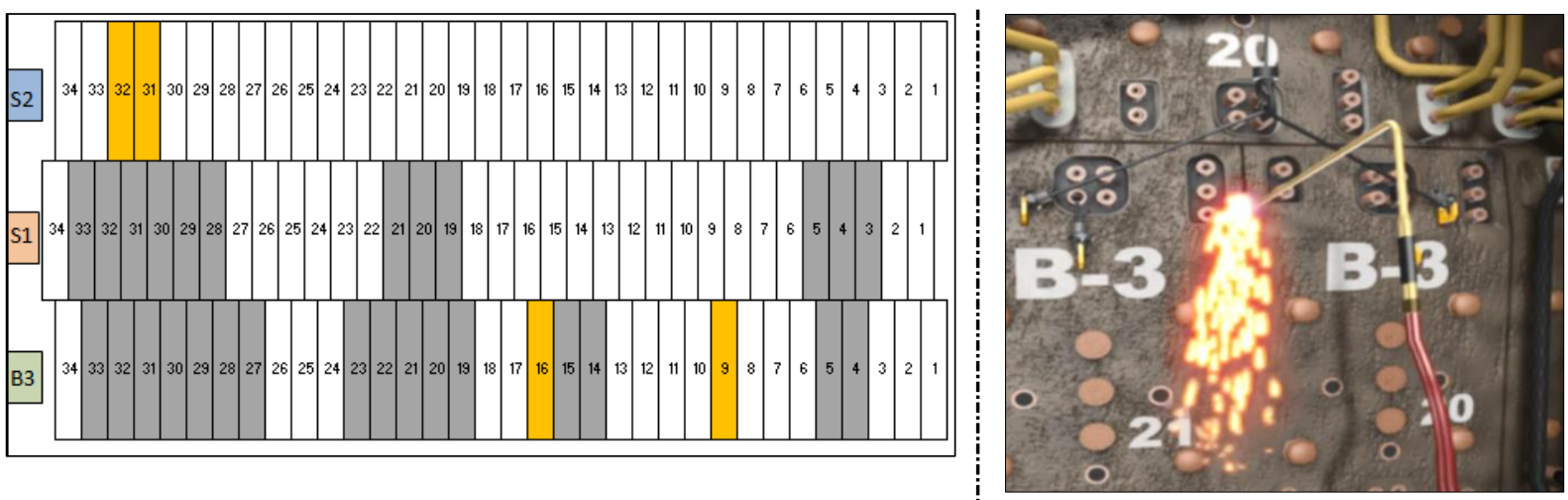

Figura 4. Mapa da troca dos staves e parte da carcaça substituída.

Os critérios adotados para priorizar os staves a serem trocados foram: (i) presença de dois ou mais tubos furados; (ii) espessura remanescente do stave $\leq 200 \mathrm{~mm}$ (situação que os tubos dos staves estão expostos à carga); (iii) condição da carcaça na região onde se encontram os staves danificados (existência de trincas, envermelhamento da carcaça etc.); (iv) localização do stave (regiões críticas de maior desgaste e/ou furo na carcaça).

O retorno à operação do Alto-Forno 3 foi no dia 09/03/2015, totalizando 340 horas de parada. Vale ressaltar duas tecnologias utilizadas para o reínicio da marcha do Alto-Forno que contribuíram para os excelentes resultados obtidos.

\section{- Uso da lança "oxi-gás"}

A utilização dessa tecnologia para o aquecimento do cadinho, melhorando as suas condições para receber o gusa e a escória produzidos no reinicio de operação, foi empregada pela primeira vez em Ipatinga.

O aquecimento do cadinho utilizando gás natural e oxigênio (lança "oxi-gás") visa manter a temperatura de chama maior que $2.000^{\circ} \mathrm{C}$ e trabalhar com excesso de gás natural, de modo a não queimar o coque presente no cadinho.

$\mathrm{O}$ aquecimento do cadinho é iniciado com o alto-forno parado e é monitorado por termopares instalados nas ventaneiras, inseridos na carga cerca de $300 \mathrm{~mm}$, figura 5. Quando a temperatura nestes termopares alcançar $900^{\circ} \mathrm{C}$, infere-se que 0 
fundo do cadinho se encontra acima de $1200^{\circ} \mathrm{C}$ e em condições de partir o altoforno. O processo de combustão ainda continua até próximo à primeira corrida.

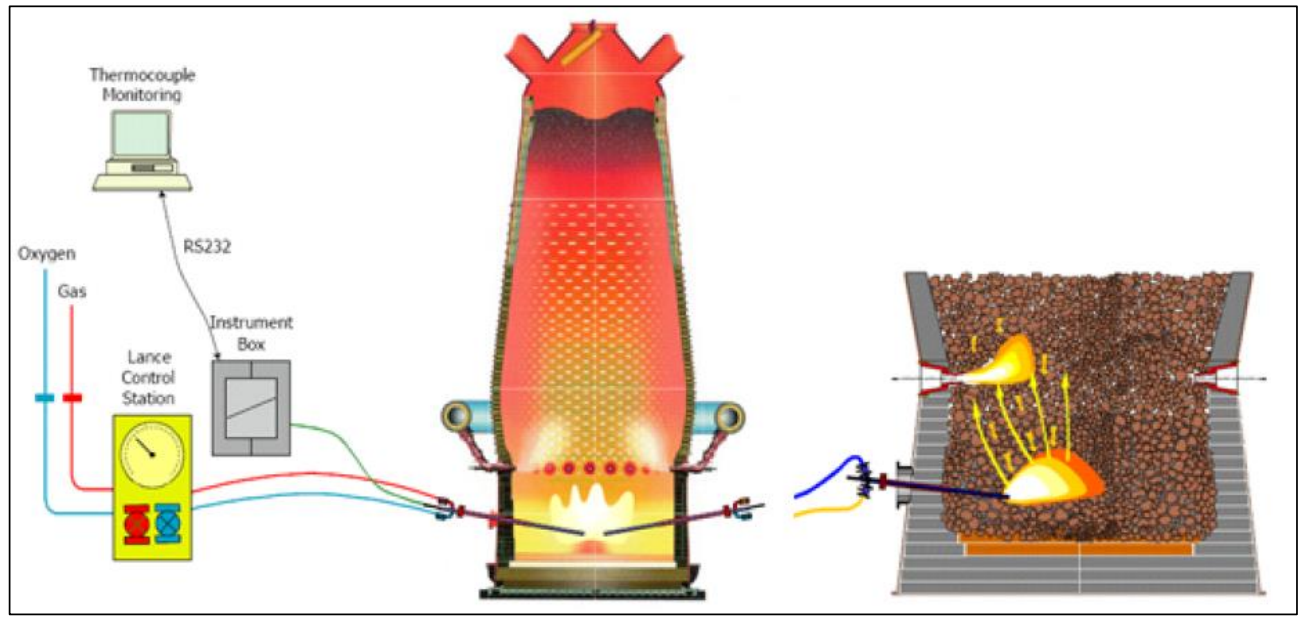

Figura 5. Conceito operacional da lança "oxi-gás".

A lança "oxi-gás" é equipada com 6 termopares ao longo do seu comprimento para indicar a presença de gusa líquido. Para evitar o desmoronamento do furo de gusa e garantir uma boa vedação contra vazamentos, foi utilizado um tubo guia, antes de inserir a lança. A prática do tubo guia deve ser repetida em outras ocasiões.

O processo de combustão é interrompido quando o termopar mais próximo ao bloco de carbono é queimado pela produção do material líquido $\left(1.100^{\circ} \mathrm{C}\right)$ ou se completarem 12 horas de combustão. Então é realizado o tamponamento do furo de gusa e, logo após, é possível iniciar a primeira corrida.

Como não foi realizada a corrida de salamandra nesta parada, o espaço para o gusa e a escória produzidos foi reduzido, e parte significativa do calor absorvido pela salamandra no reinício de marcha. Por estes motivos, além de usar duas lanças "oxi-gás", o Alto-Forno 3 entrou em operação com a metade das ventaneiras fechadas, figura 6 .

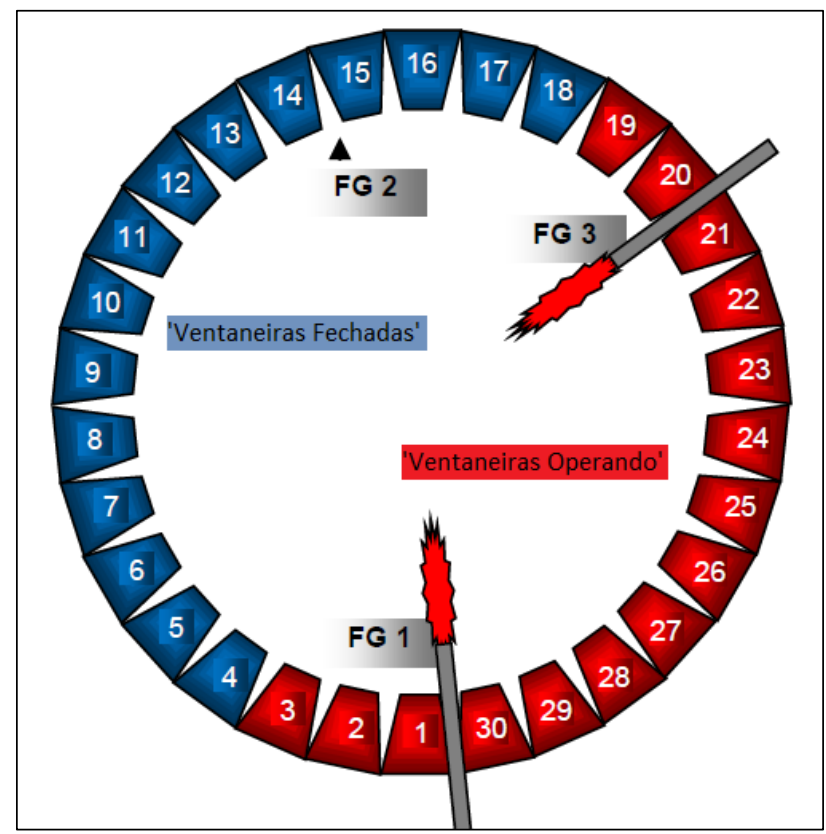

Figura 6. Condição das ventaneiras e posicionamento das lanças "oxi-gás" no reinício da marcha do Alto-Forno 3. 


\section{- Uso do "copo cerâmico"}

Para o isolamento das ventaneiras foram usados "copos cerâmicos" (figura 7), cuja retirada é realizada com o forno em operação, utilizando-se um tubo introduzido pelo check valve de injeção de gás natural ou carvão, até que este encoste no fundo da peça. Em seguida é dado um golpe na extremidade externa do tubo. Em caso de impossibilidade da abertura de alguma ventaneira, o alto-forno deve ser parado para este fim.
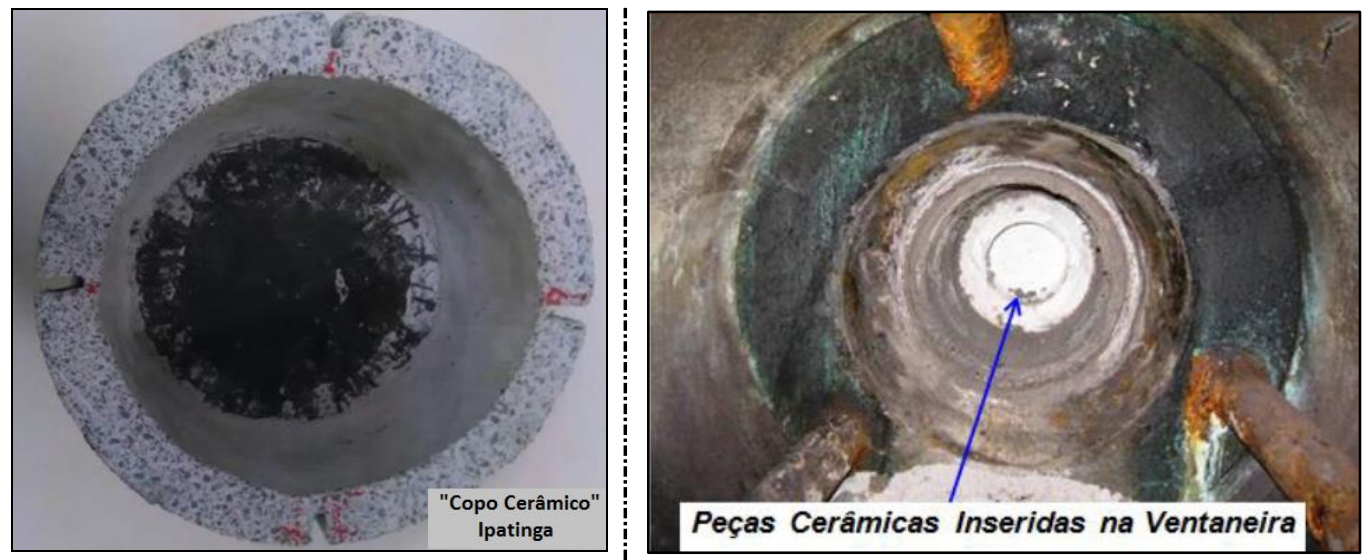

Figura 7. "Copos cerâmicos" utilizados no isolamento das ventaneiras no reinício da marcha do AltoForno 3.

A fabricação das peças e o seu posicionamento no interior da ventaneira devem ser criteriosamente monitorados para garantir sucesso na operação. O maior ganho ao utilizar os "copos cerâmicos" nessa situação é a possibilidade de retorno operacional do alto-forno apenas com algumas ventaneiras, sem a necessidade de novas paradas para a abertura das demais ventaneiras, face aos riscos operacionais de cada parada com relação à condição do cadinho (baixa reserva térmica).

No caso do Alto-Forno 3, após a primeira corrida, foi observada uma rápida recuperação operacional e, no quarto dia após o blow in, todas as ventaneiras já estavam operando, tendo sido necessário realizar apenas uma parada para abertura das ventaneiras 13 e 14. A produção real foi significativamente superior àquela prevista (figura 8) e a produção mensal prevista foi alcançada 10 dias antes do esperado.

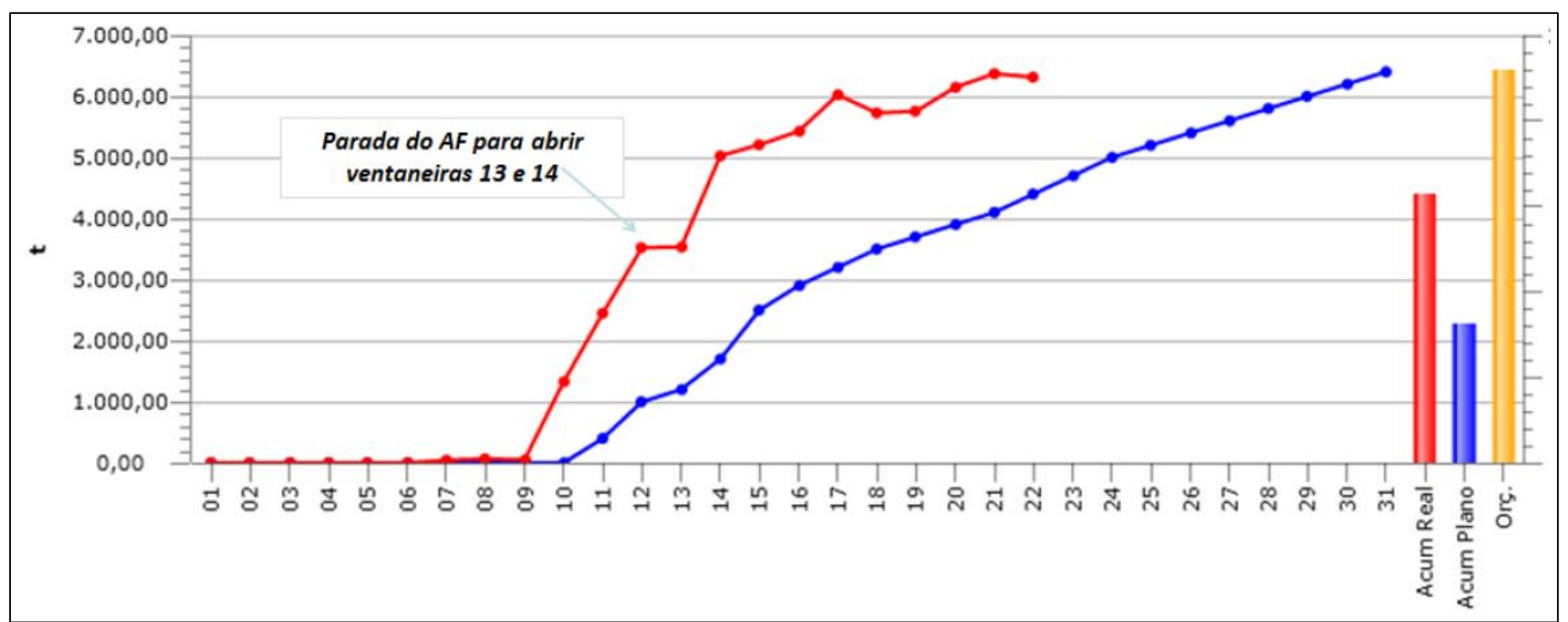

Figura 8. Evolução da produção (t/dia) do Alto-Forno 3 em seu retorno operacional após parada para troca de staves e parte da carcaça (produção real versus produção prevista). 


\subsection{Cadinho}

O cadinho do Alto-Forno 3 é constituído basicamente de carbono ultra super microporo. Os furos de corrida são em blocos de carbono super microporo, com altura de fundo do cadinho em relação ao nível dos furos de gusa dentro dos conceitos de flutuação do homem morto, o que diminui a tendência de desgaste lateral [2]. O sistema de refrigeração é por staves, com fluxo de água horizontal realizado em duas direções, para garantir a completa refrigeração do cadinho. $\mathrm{Na}$ figura 9 é apresentado o perfil original do cadinho (espessura do refratário $\sim 2.000 \mathrm{~mm}$ ), incluindo os diferentes tipos de refratários que compõem 0 seu revestimento.

Em março/2009, ocorreram grandes elevações nas temperaturas da parede do cadinho, que resultaram em desgaste dos blocos e elevada instabilidade na marcha do Alto-Forno. Assim, as medidas de controle foram intensificadas e novas soluções para conter as elevações de temperatura foram adotadas.

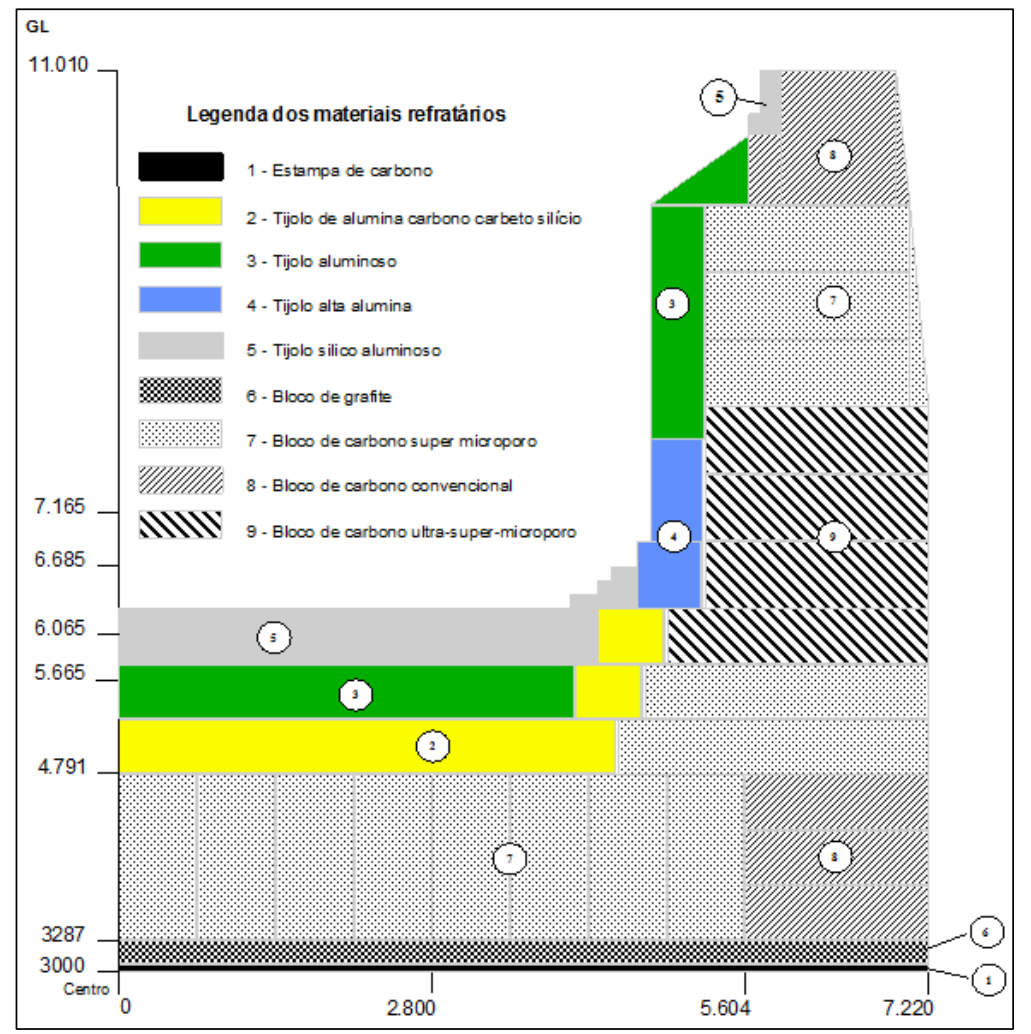

Figura 9. Perfil original do cadinho do Alto-Forno 3 e os tipos de refratários que compõem o seu revestimento.

\subsubsection{Modelo de desgate do cadinho}

O acompanhamento da espessura da parede do cadinho é realizado por meio de um modelo matemático baseado no fluxo de calor $(\mathrm{Q}=\lambda \Delta \mathrm{T} / \Delta \mathrm{H})$, desenvolvido pelo Centro de Pesquisa e Desenvolvimento da Usiminas. O programa utiliza as temperaturas registradas por termopares inseridos ao longo de toda parede do cadinho e em sua soleira, para fornecer informações como a espessura do refratário remanescente e da camada de proteção formada na face quente dos blocos (figura 10). Essa ferramenta é fundamental no monitoramento da estabilidade do cadinho. Os resultados do modelo, juntamente com o acompanhamento das tendências em temperatura do cadinho, são fundamentais para tomada de ações. 


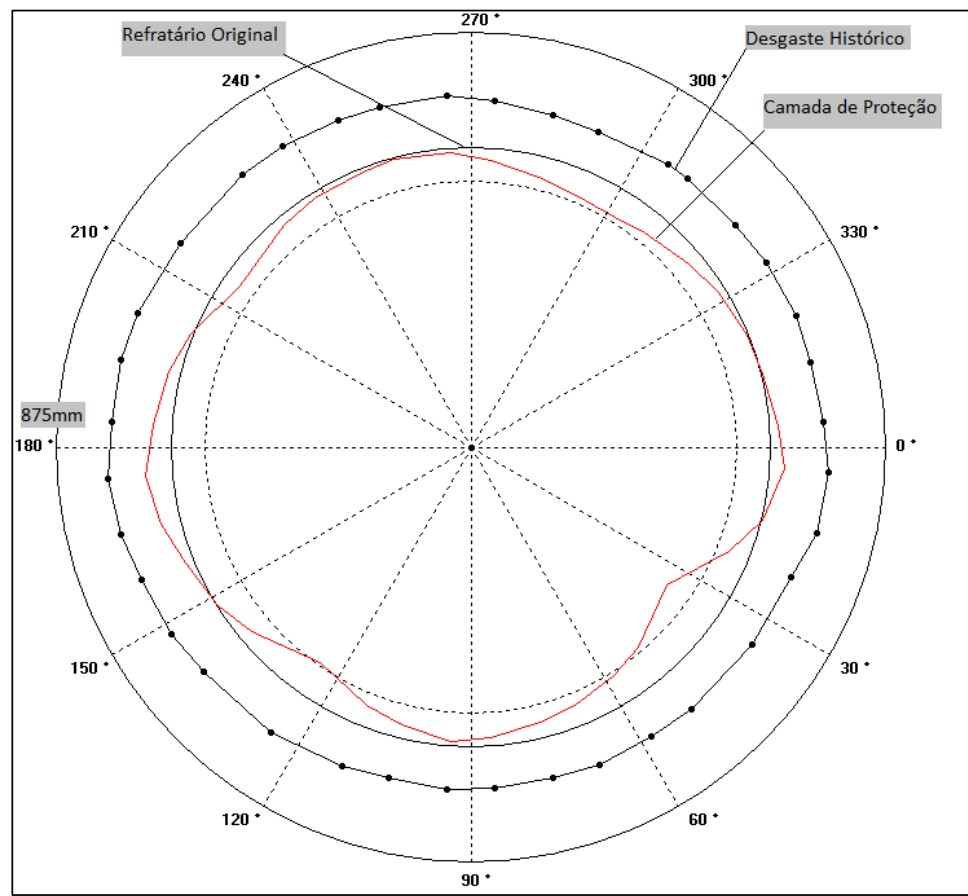

Figura 10. Perfil de desgaste do Alto-Forno 3 no GL+7165 fornecido pelo modelo de desgaste (junho/2017).

A região mais crítica em termos de desgate do refratário está localizada no GL+7165 (ground level), ângulo 175으, com uma espessura de bloco igual a $875 \mathrm{~mm}$ (área do furo de gusa 2), sendo a espessura limite para final da campanha igual a $400 \mathrm{~mm}$. Ressalta-se que, desde maio/2009, não ocorreu nenhum desgaste nesta região e as ocorrências de elevações de temperatura do cadinho se tornaram menos frequentes e mais brandas, resultado de um acompanhamento diário dos parâmetros e do reforço na aplicação preventiva de ferramentas e práticas visando a preservação do cadinho.

\subsubsection{Ações para preservação e controle com relação ao desgaste do cadinho}

Algumas ações praticadas no sentido de evitar a elevação de temperatura do cadinho e controlar situações críticas que podem resultar em desgaste dos blocos são:

- limitação da produtividade;

- controle da qualidade das matérias-primas enfornadas;

- comprimento visado dos furos de gusa $\geq 3.500 \mathrm{~mm}$;

- injeção de óxido de titânio (se necessário) via carvão pulverizado ou aplicado pontualmente nos pontos quentes;

- alteração na qualidade química do gusa e escória em caso de elevação de temperatura do cadinho: maior teor de silício, redução do teor de manganês e maior basicidade da escória;

- injeção de massa carbonosa entre o bloco de carbono e os staves, garantindo a refrigeração dos blocos (aumento da troca térmica);

- redução do diâmetro ou fechamento das ventaneiras nas regiões críticas;

- operação all coke, redução do ritmo ou parada do Alto-Forno 3 em casos mais críticos;

- monitoramento e atuação na refrigeração da soleira e dos staves. 


\section{PERPECTIVAS FUTURAS}

Com base nos resultados do modelo matemático de desgaste do cadinho, sem considerar acidentes operacionais, foi estimado que a espessura mínima limite do refratário igual a $400 \mathrm{~mm}$ será atinginda em 2022 (figura 11). É notável que os resultados obtidos com relação ao desgaste do bloco superaram as expectativas, já que a curva do desgaste calculado, baseada em produtividade, previa o fim de vida útil para 2017. A curva do desgaste no $G L+7165$, ângulo 175을 que vinha evoluindo de forma acelerada, permaneceu estável nos últimos 9 anos, resultado das ações tomadas para a preservação do Alto-Forno.

A reforma do Alto-Forno 3 está prevista para 2021, garantindo que esta ocorra antes do período provável do fim de vida útil dos blocos de carbono e em alinhamento com as reformas dos Altos-Fornos's 1 e 2 . Além disso, está programada uma $2^{a}$ troca de staves em 2018 (32 staves), visando garantir a refrigeração e estabilidade operacional até a reforma.

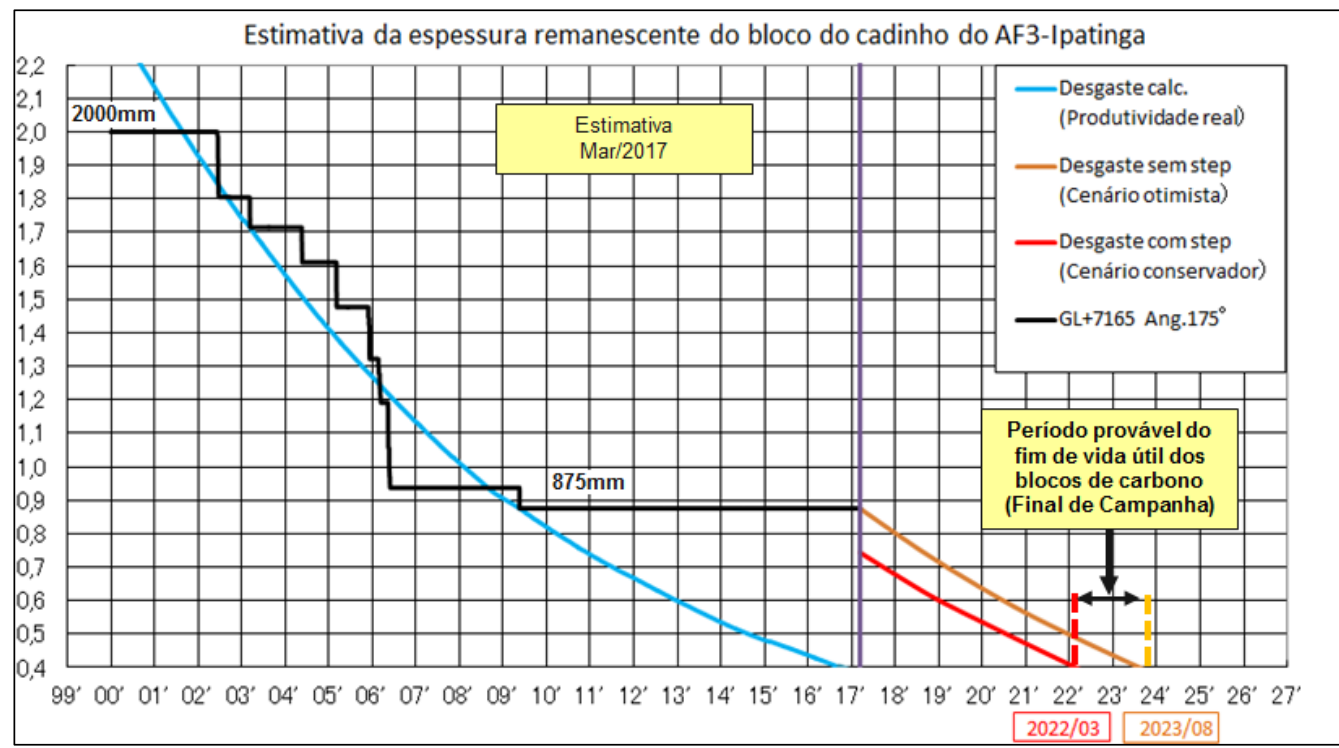

Figura 11. Projeção do final da 4ª campanha do Alto-Forno 3 a partir da espessura mais crítica do bloco de carbono do cadinho.

Na figura 12 observa-se o comparativo da produtividade versus tempo de vida útil entre altos-fornos a nível mundial. A produtividade média obtida na $3^{\mathrm{a}}$ campanha do Alto-Forno 3 (2,42 t/d.m $\mathrm{m}^{3}$ - 12 anos em operação) constitui-se um dos melhores resultados da siderurgia mundial. Já na atual campanha (4ํㅡㄹ campanha), os esforços estão voltados para o prolongamento da vida útil do Alto-Forno, com consequente redução nos níveis de produção praticados.

Os parâmetros planejados para a 5a campanha também são apresentados: manutenção do volume interno, produtividade média igual a 2,38 t/d.m $\mathrm{m}^{3}$ e 20 anos em operação.

Destaca-se que além das ações voltadas para a preservação do cadinho e do sistema de refrigeração, a tendência de piora dos minérios de ferro aliada à extinção de granulados exigirão uma nova forma de operação do forno, desafiando a equipe técnica a buscar alternativas para manter a produtividade planejada. Para tanto, será necessária a utilização de cargas metálicas mais elaboradas. 


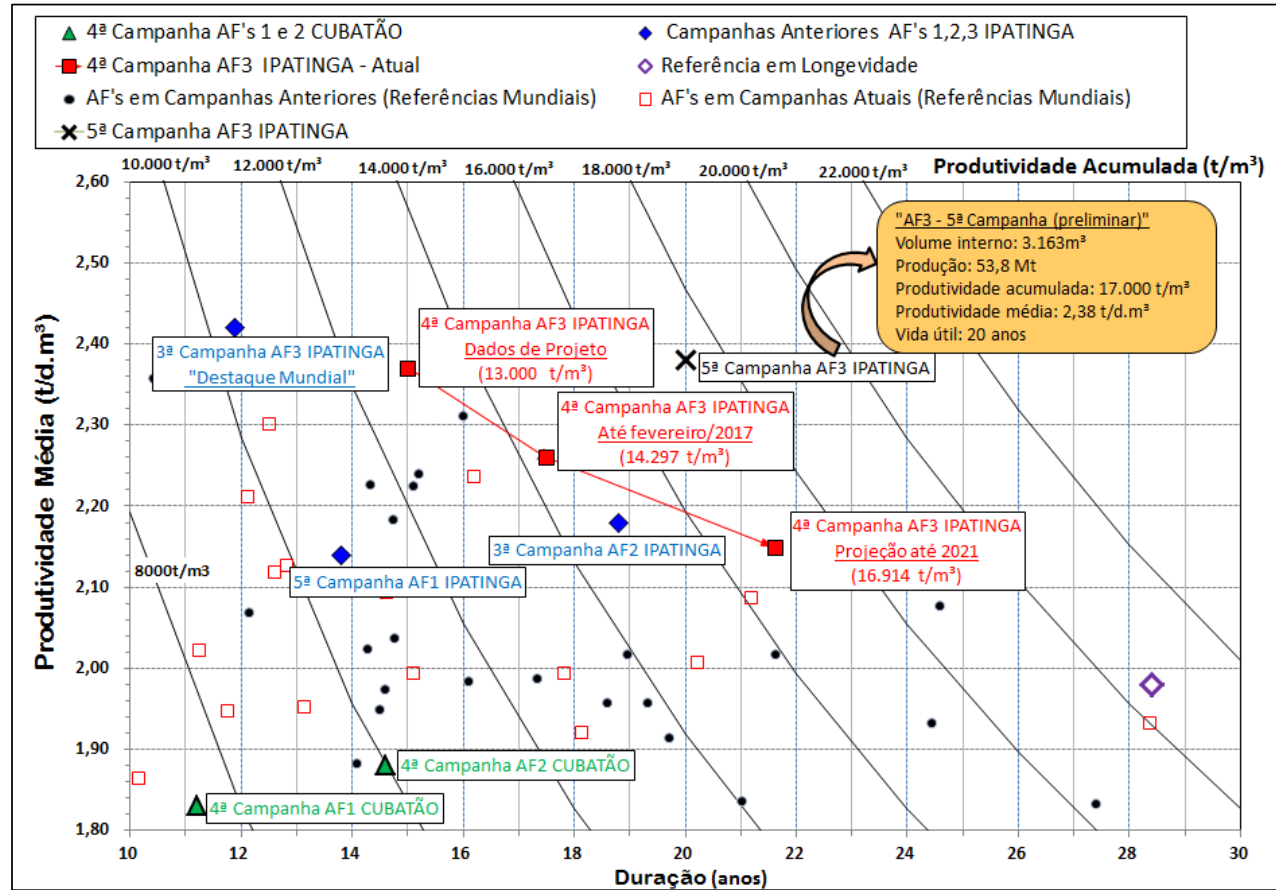

Figura 12. Comparativo da produtividade versus tempo de vida útil entre altos-fornos a nível mundial.

\section{CONCLUSÃo}

Vislumbrou-se a necessidade de operar o Alto-Forno $3 \mathrm{com}$ foco nas medidas de preservação já praticadas e na adoção de novas, de forma a manter a competitividade no cenário de prolongamento de vida útil. Os resultados da campanha atual superam as expectativas, indicando que, em termos de produtividade média e duração de campanha, a $4^{\mathrm{a}}$ campanha se destacará nesse contexto.

Visando a preservação do cadinho, subsidiadas pelos resultados do modelo de desgaste, ações como a limitação da produtividade e injeção de óxido de titânio, têm minimizado as ocorrências de elevação de temperatura. No sistema de refrigeração, a instalação de by pass nos tubos furados, instalação de cigar coolers, injeção de massa e a $1^{\underline{a}}$ troca de staves, foram medidas necessárias para manter a eficiência da refrigeração, preservar a carcaça, reduzir o número de paradas de sopro e evitar acidentes operacionais. Além disso, está programada uma $2^{\underline{a}}$ troca de staves em 2018. O conjunto dessas ações contribuem para garantir o prolongamento da vida útil do Alto-Forno 3.

Como resultado destes esforços, espera-se uma vida útil de 22 anos nesta $4^{\text {a }}$ campanha do Alto-Forno 3, superando em 7 anos a duração prevista no seu projeto, e em aproximadamente 10 anos o tempo de operação na campanha anterior.

\section{REFERÊNCIAS}

1 Carvalho, S. J.; Manso, G. A. C.; Fernandes, M. V.; Gandra, B. F. Evolução Operacional do Alto-Forno 3 da Usiminas Ipatinga em sua 4a Campanha. 39을 Seminário de Redução de Minério de Ferro e Matérias-Primas e 10ํㅗ Simpósio Brasileiro de Minério de Ferro. Ouro Preto, MG, 2009.

2 Gandra, B. F. Desenvolvimento de Modelo Matemático do Fluxo de Líquidos no Cadinho do Alto-Forno. Dissertação de Mestrado em Engenharia Metalúrgica e de Minas, Universidade Federal de Minas Gerais, 2007. 